\title{
The role of galectins in obstetrics with particular emphasis on premature preterm rupture of membranes
}

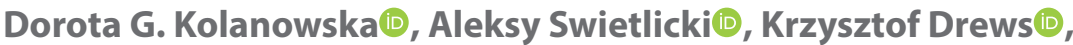 \\ Agnieszka Seremak-Mrozikiewiczi(D)
}

\author{
Division of Perinatology and Women's Diseases, Poznan University of Medical Sciences, Poznan, Poland
}

\begin{abstract}
Premature rupture of membranes (PPROM) affects about $4 \%$ of pregnancies and remains the main cause of preterm delivery (PTD). We currently lack a method for screening patients at high risk of pPROM as well as causal treatment for this yet not fully understood pathology of pregnancy. Promising, potential markers are proteins from a family of lectins-galectins. To date, 13 subtypes have been identified in humans. Particular galectins inhibit the mother's immune response to the fetus, thus enabling the maintenance of pregnancy and delivering at term. So far, the role of some galectins has been proven in relation to early pregnancy complications, hypertension and preeclampsia, fetal growth disturbances (including fetuses small for gestational age, fetal growth restriction and macrosomia) and even in physiological processes which occur during healthy pregnancy. In reference to PPROM galectins seem to be linked to pathomechanisms leading to weakening of the structure of membranes and in result their rupture. Examination of galectins appears to be crucial for understanding certain pathologies of pregnancy and gives hope for the effective identification of risk groups and future causal treatment. Key words: pPROM; galectins; preeclampsia; FGR; SGA
\end{abstract}

Ginekologia Polska 2021; 92, 10: 731-734

\section{INTRODUCTION}

Preterm premature rupture of fetal membranes (PPROM) is defined as a rupture of membranes before the end of $37^{\text {th }}$ gestational week. It is estimated that this problem affects about $4 \%$ of pregnancies and is responsible for almost half of preterm deliveries (PTD) [1]. Despite great advances in perinatal care in recent decades, the number of premature births caused by PPROM has been constantly increasing [2]. We currently have numerous methods to facilitate the diagnosis (e.g., rapid tests that allow detection of IGFBP-1 or PAMG-1 from a vaginal swab sample, tests for vaginal $\mathrm{pH}$ ), but we still do not have an effective tool to identify PPROM likelihood markers. Several risk factors have been recognized, including: bacterial or fungal infection in the reproductive tract at each stage of pregnancy, multiple pregnancy, polyhydramnion, vaginal bleeding in the first trimester, and socioeconomic factors (including mainly cigarette smoking) [3], however, the exact pathophysiological mechanisms are not yet discovered. The currently prevailing view is that PPROM is a complication caused by the disease of the membranes themselves, in which the key role is played by oxidative stress [4], leading first to the weakening of the membrane structure and then to their rupture. Therefore, it is believed that the inflammatory process is secondary to PPROM, because due to the microdamage that occur, the membranes of the fetus become the gateway to potential infection [5]. The putative markers which may effectively screen patients at high risk for $\mathrm{pPROM}$ are galectins.

Galectins are a group of proteins from a family of lectins, characterized by the ability to bind B-galactosides due to the presence of a sugar recognition domain - CRD (carbohydrate recognition domain) in their structure [6]. To date, 13 subtypes have been identified in humans [7]. They differ in structure and functions - from migration, through cell growth and differentiation, tolerance and immune response [8], to directing a cell to apoptosis [9]. Galectins are a subject of research in many fields of medicine, especially oncology and cardiology. Also in obstetrics, there are reports of their key role in, for example, the regulation of trophoblast development, migration and invasion as well as placental

\footnotetext{
Corresponding author:

Dorota G. Kolanowska

Division of Perinatology and Women's Diseases, Poznan University of Medical Sciences, Poznan, Poland

e-mail: d.kolanowska@onet.eu
} 
angiogenesis [10]. They are also responsible for signaling to direct cells of the fetal membranes to apoptosis in case of rupture of membranes [11]. Therefore, galectins are accountable for the proper course of pregnancy. In relation to clinical trials in obstetrics and gynecology, their most interesting role seems to be the modulation of the immune response. Some galectins inhibit the mother's immune response to the fetus, thus enabling the maintenance of pregnancy and delivering at term [12]. That is why their in-depth examination and learning mechanisms of action appears to be crucial for understanding some pathologies of pregnancy and gives hope for the effective identification of risk groups and future causal treatment.

\section{GALECTINS IN OBSTETRICS}

In the present light, pregnancy is an allogeneic transplant that leads to mild chronic inflammation in normal pregnancy $[13,14]$. The expression of individual galectins was described in, inter alia, the placenta, fetal membranes, as well as in maternal blood, and they appear to be involved in the process of fetal tolerance by the mother, including regulation of the inflammatory response associated with pregnancy $[7,15]$.

\section{Early pregnancy}

Increased expression of individual galectins can be noticed at the earliest stages of pregnancy. The expression of galectin-1,-3 and -9 has already been described in relation to embryogenesis [9], and together with galectin-15 they also play an important role in the implantation process, enabling adhesion of the blastocyst to the uterine epithelium [16]. Galectin expression affects not only trophoblast but also maternal immune cells. Galectin-1, inter alia, inhibits the proliferation of T-lymphocytes, leads to the apoptotic pathway of activated CD8 +, Th1 and Th17 cells, and inactivates pro-inflammatory cytokines $[17,18]$. It also plays an important role in the apoptosis of activated T-cells present in the decidua [19], thus contributing to the maintenance of maternal tolerance to the fetus $[15,19]$.

A study on a mouse model showed that the mice exposed to stress had lower expression of decidual galectin 1, which resulted in more frequent loss of pregnancy. Interestingly, this effect was reversible after exogenous administration of recombinant galectin-1, which may in the future be associated with the possibility of a potential causal treatment preventing early pregnancy loss [15].

Galectin-1 is also involved in the process of trophoblast invasion and placental angiogenesis. It stimulates the production of proangiogenic factors, thus ensuring the correct placental synthesis [20].

Galectin-9 creates an immunologically friendly environment for implantation thanks to its role in inducing the transformation of peripheral NK cells (natural killer) into uNK (uterine natural killer). A decreased number of uNK cells has been found in the case of miscarriage in the early stages of pregnancy, which suggests an important role of galectin-9 in the maintenance of pregnancy [21].

The role of other galectins, including in particular galectin-3, $-8,-13,-14,-15,-16$ and -17 , also seems to be important in the processes occurring in early pregnancy. However, they are less known but still of interest to both molecular biologists and clinicians.

\section{Hypertension and preeclampsia}

Preeclampsia is the most studied complication of pregnancy in terms of changes in the expression and concentration of galectins in several body fluids. It is also one of the most serious complication which affects approximately $7 \%$ of pregnancies and is associated with many aftermaths, including the risk of death for both the mother and the fetus [22]. Overexpression of galectin-1 and -3 and decreased -13 were found in decidua and trophoblast cells both in patients with mild and severe preeclampsia and in HELLP (hemolysis, elevated liver enzymes, low platelet count) syndrome [23], which is related to abnormal trophoblast invasion leading to those complications [24]. Interestingly, the abovementioned deviations from the norm already occur in the early stages of pregnancy, which will develop preeclampsia in the later weeks [25]. In the peripheral blood of a mother with developing preeclampsia, a decreased amount of galectin-1 and -13 can be observed, which may serve as a marker of early preeclampsia in the future [26].

\section{Fetal growth disturbances}

Recent studies on the relationship of galectins with fetuses too small for gestational age (SGA) suggest that the smaller the child is compared to gestational age, the higher the concentration of galectin-3 in the umbilical cord blood, which may suggest a pivotal role of inflammation in this pathology. Similarly, in case of intrauterine growth restriction (IUGR), elevated concentrations of this galectin in the umbilical cord blood were found. This likely reflects the inflammatory response caused by chronic fetal hypoxia [27]. On the other hand, Hutter et al. proved that in the placenta of IUGR-complicated fetuses there is a sex-dependent, statistically significant overexpression of some galectins (galectin 4, 8 and 9 in male and 9 and 12 in female) compared to placenta of fetuses with normal birth weight [28]. The same research group in another study confirmed the association of reduced galectin-3 expression in fetal placenta with IUGR, regardless of fetal gender [29]. A parallel study by Boutsikou et al. [30] showed a correlation between the concentration of galectin- 1 and galectin-3 in the blood plasma of multiparous women with fetuses with both macrosomia and IUGR. 


\section{Physiological delivery at term}

The role of galectins has been investigated not only in the context of pathological pregnancy, but also in the physiological processes leading to childbirth. Delivery at term in a healthy woman is associated with local pro-inflammatory changes that initiate the opening and shortening of the cervix and contractions of the uterine muscle [31,32]. During induction of labor with oxytocin, an increased concentration of galectin-7 is observed, while a decreased expression of galectin- 9 is noted at the site of rupture of fetal membranes [31]. Moreover, the expression of galectin-1 is the highest in placenta in term pregnancies compared to its earlier stages. Galectin-1 is a placenta-specific protein, achieving about 28 times greater expression in the placenta compared to other body tissues [11].

\section{Galectins in premature rupture of membranes}

Premature rupture of the membranes is responsible for almost half of the preterm deliveries [1]. It is also one of the few pathologies of pregnancy where the exact pathophysiological mechanism is unknown. We do not have specific methods of prevention of PPROM and, consequently, causal treatment. It is nowadays believed that research regarding expression and concentration of galectins in different tissues and body fluids may hopefully answer at least some questions concerning pPROM. The expression of galectin-1, $-7,-9,-13,-14,-16$ and -17 is found in the fetal membranes themselves, but their exact functions and regulation mechanisms in this structure are unknown [7, 33].

It is assumed that there is a relationship between galectins and premature rupture of membranes, which is associated in up to $75 \%$ with bacterial infection of the membranes and/or amniotic fluid [34]. Galectin-1 is the most studied galectin in this pathology. It has been identified in all types of cells that build fetal membranes, including amniotic epithelial cells, chorionic trophoblast or chorio-vascular mesenchymal cells. Previous studies suggest that during pPROM without membrane infection, its mRNA expression in fetal membranes is comparable to that observed in healthy pregnant women, while it increases in the case of pPROM with histopathologically confirmed inflammation of the membranes. Overexpression of galectin-1 in fetal membranes might be linked to weakening of their structure, increased susceptibility to infections and ultimately their rupture. Moreover, it is believed that galectin- 1 serves as an active barrier protecting the fetus against bacterial infection and that it facilitates phagocytosis of excessively produced maternal neutrophils [33].

Recent studies also suggest a role of galectin-3 in PPROM. It is a pro-inflammatory molecule which, similar to galectin-1, regulates the immune response. Its mechanism of action is inhibition of apoptosis of macrophages and monocytes. It also is their chemoattractant. However, the relationship between $\mathrm{PPROM}$ and galectin-3 concentration was proven only in the case of histopathologically confirmed inflammation of the membranes, where the expression of galectin-3 was statistically significantly increased in the cytoplasm of cells building fetal membranes [35]. It is worth mentioning that due to their strong immunosuppressive properties, fetal membranes are used in ophthalmology to treat corneal injuries and in the transplantation of skin fragments, where they support the healing process and reduce the risk of transplant rejection. The galectins (mainly 1 and 3) are most likely responsible for the mentioned immunosuppressive effects [36].

New hope was provided by recent reports on confirmed differences in maternal galectin- 1 and -3 concentrations in mother's blood in PPROM patients compared to healthy pregnant women. Kaya et al. indicate that the above-mentioned galectins occur in statistically significantly higher concentrations in the serum of pregnant women with pPROM compared to healthy patients, regardless of the inflammation of the membranes or other inflammatory factors [37].

In the context of rupture of membranes, there are also references to galectin- 9 , whose expression in the chorion is reduced at the site of weakening of the membrane structure, which consequently leads to their rupture [31].

\section{CONCLUSIONS}

Galectins are ubiquitous proteins with multidirectional regulatory functions. Their expression is crucial both for the processes related to early pregnancy and for pathologies that appear along with its advancement. Research on the role of galectins in the pathophysiology of pregnancy is still at an early stage and requires further in-depth analysis. However, preliminary results suggest that some of them are promising candidates as potential markers of pre-eclampsia, SGA and IUGR, and may also be used as a causal treatment for recurrent and threatening miscarriages in the future. Galectins, in particular galectin 1, 3 and 9, may be a factor causing a cascade of unfavorable pathophysiological reactions leading to $\mathrm{PPROM}$. They are also a promising object of research towards the discovery of markers allowing to distinguish pregnancies from groups at risk of this pathology.

\section{Conflict of interest}

The authors state that there are no conflicts of interest to disclose.

\section{REFERENCES}

1. Mercer BM, Crouse DT, Goldenberg RL, et al Eunice Kennedy Shriver National Institute of Child Health and Human Development Maternal-Fetal Medicine Units Network. The antibiotic treatment of PPROM study: systemic maternal and fetal markers and perinatal outcomes. Am J Obstet Gynecol. 2012; 206(2): 145.e1-145.e9, doi: 10.1016/j.ajog.2011.08.028, indexed in Pubmed: 22000668. 
2. Montenegro D, Romero R, Kim SS, et al. Expression patterns of microRNAs in the chorioamniotic membranes: a role for microRNAs in human pregnancy and parturition. J Pathol. 2009; 217(1): 113-121, doi: 10.1002/path.2463, indexed in Pubmed: 18991333.

3. Silverman R, Wojtowycz M. Risk factors in premature rupture of membranes. Primary Care Update for OB/GYNS. 1998; 5(4): 181, doi: 10.1016/s1068-607x(98)00092-4.

4. Tuuli MG, Longtine MS, Nelson DM. Review: Oxygen and trophoblast biology--a source of controversy. Placenta. 2011; 32 Suppl 2: S109-S118, doi: 10.1016/j.placenta.2010.12.013, indexed in Pubmed: 21216006.

5. Richardson LS, Vargas G, Brown T, et al. Discovery and characterization of human amniochorionic membrane microfractures. Am J Pathol. 2017; 187(12): 2821-2830, doi: 10.1016/j.ajpath.2017.08.019, indexed in Pubmed: 28939208.

6. Cooper D. Galectinomics: finding themes in complexity. Biochimica et Biophysica Acta (BBA) - General Subjects. 2002; 1572(2-3): 209-231, doi: 10.1016/s0304-4165(02)00310-0.

7. Than NG, Romero R, Goodman M, et al. A primate subfamily of galectins expressed at the maternal-fetal interface that promote immune cell death. Proc Natl Acad Sci U S A. 2009; 106(24): 9731-9736, doi: 10.1073/pnas.0903568106, indexed in Pubmed: 19497882.

8. Blois SM, Conrad ML, Freitag N, et al. Galectins in angiogenesis: consequences for gestation. J Reprod Immunol. 2015; 108: 33-41, doi: 10.1016/j.jri.2014.12.001, indexed in Pubmed: 25622880.

9. Cumming RD, Liu FT, Vasta GR. Galectins. In:Varki A, Cummings RD, Esko JD, et al. ed. Essentials of Glycobiology. Cold Spring Harbor Laboratory Press, New York 2025.

10. Blois SM, Dveksler G, Vasta GR, et al. Pregnancy galectinology: insights into a complex network of glycan binding proteins. Front Immunol. 2019; 10: 1166, doi: 10.3389/fimmu.2019.01166, indexed in Pubmed: 31231368.

11. El-Azzamy $\mathrm{H}$, Balogh $\mathrm{A}$, Romero R, et al. Characteristic changes in decidual gene expression signature in spontaneous term parturition. J Pathol TransI Med. 2017; 51(3): 264-283, doi: 10.4132/jptm.2016.12.20, indexed in Pubmed: 28226203.

12. Jerzak M, Bisch of P. Apoptosis in the first trimester human placenta: the role in maintaining immune privilege at the maternal-foetal interface and in the trophoblast remodelling. European Journal of Obstetrics \& Gynecology and Reproductive Biology. 2002; 100(2): 138-142, doi: 10.1016/s0301-2115(01)00431-6.

13. Arck PC, Hecher K. Fetomaternal immune cross-talk and its consequences for maternal and offspring's health. Nat Med. 2013; 19(5): 548-556, doi: 10.1038/nm.3160, indexed in Pubmed: 23652115.

14. Redman CWG, Sargent IL. Circulating microparticles in normal pregnancy and pre-eclampsia. Placenta. 2008; 29 Suppl A: S73-S77, doi: 10.1016/j.placenta.2007.11.016, indexed in Pubmed: 18192006.

15. Blois SM, Ilarregui JM, Tometten $M$, et al. A pivotal role for galectin-1 in fetomaternal tolerance. Nat Med. 2007; 13(12): 1450-1457, doi: 10.1038/nm1680, indexed in Pubmed: 18026113.

16. Tirado-González I, Freitag N, Barrientos G, et al. Galectin-1 influences trophoblast immune evasion and emerges as a predictive factor for the outcome of pregnancy. Mol Hum Reprod. 2013; 19(1): 43-53, doi: 10.1093/molehr/gas043, indexed in Pubmed: 23002109.

17. Molvarec A, Blois SM, Stenczer B, et al. Peripheral blood galectin-1-expressing $T$ and natural killer cells in normal pregnancy and preeclampsia. Clin Immunol. 2011; 139(1): 48-56, doi: 10.1016/j.clim.2010.12.018, indexed in Pubmed: 21292557.

18. Garín MI, Chu CC, Golshayan D, et al. Galectin-1: a key effector of regulation mediated by CD4+CD25+ T cells. Blood. 2007; 109(5): 2058-2065, doi: 10.1182/blood-2006-04-016451, indexed in Pubmed: 17110462.

19. Kopcow HD, Rosetti $F$, Leung $Y$, et al. $T$ cell apoptosis at the maternal-fetal interface in early human pregnancy, involvement of galectin-1. Proc Natl Acad Sci U S A. 2008; 105(47): 18472-18477, doi: 10.1073/pnas.0809233105, indexed in Pubmed: 19011096.

20. Freitag N, Tirado-González I, Barrientos G, et al. Interfering with Gal-1-mediated angiogenesis contributes to the pathogenesis of preeclampsia. Proc Natl Acad Sci U S A. 2013; 110(28): 11451-11456, doi: 10.1073/pnas.1303707110, indexed in Pubmed: 23798433.
21. Li YH, Zhou WH, Tao Yu, et al. The Galectin-9/Tim-3 pathway is involved in the regulation of NK cell function at the maternal-fetal interface in early pregnancy. Cell Mol Immunol. 2016; 13(1): 73-81, doi: 10.1038/cmi.2014.126, indexed in Pubmed: 25578313.

22. Sibai B, Dekker G, Kupferminc M. Pre-eclampsia. The Lancet. 2005; 365(9461): 785-799, doi: 10.1016/s0140-6736(05)71003-5, indexed in Pubmed: 15733721.

23. Shankar R, Johnson MP, Williamson NA, et al. Molecular markers of preterm labor in the choriodecidua. Reprod Sci. 2010; 17(3): 297-310, doi: 10.1177/1933719109353454, indexed in Pubmed: 20009011.

24. Jeschke U, Mayr D, SchiessI B, et al. Expression of galectin-1,-3 (gal-1, gal3 ) and the Thomsen-Friedenreich (TF) antigen in normal, IUGR, preeclamptic and HELLP placentas. Placenta. 2007; 28(11-12): 1165-1173, doi: 10.1016/j.placenta.2007.06.006, indexed in Pubmed: 17664004.

25. Kliman HJ, Sammar M, Grimpel Yl, et al. Placental protein 13 and decidual zones of necrosis: an immunologic diversion that may be linked to preeclampsia. Reprod Sci. 2012; 19(1): 16-30, doi: 10.1177/1933719111424445, indexed in Pubmed: 21989657.

26. Huppertz B, Meiri H, Gizurarson S, et al. Placental protein 13 (PP13): a new biological target shifting individualized risk assessment to personalized drug design combating pre-eclampsia. Hum Reprod Update. 2013; 19(4): 391-405, doi: 10.1093/humupd/dmt003, indexed in Pubmed: 23420029.

27. Demmert $\mathrm{M}$, Faust $\mathrm{K}$, Bohlmann $\mathrm{MK}$, et al. Galectin-3 in cord blood of term and preterm infants. Clin Exp Immunol. 2012; 167(2): 246-251, doi: 10.1111/j.1365-2249.2011.04509.x, indexed in Pubmed: 22236000.

28. Hutter S, Knabl J, Andergassen U, et al. Fetal gender specific expression of tandem-repeat galectins in placental tissue from normally progressed human pregnancies and intrauterine growth restriction (IUGR). Placenta. 2015; 36(12): 1352-1361, doi: 10.1016/j.placenta.2015.09.015, indexed in Pubmed: 26462906.

29. Hutter S, Knabl J, Andergassen U, et al. Placental expression patterns of galectin-1, galectin-2, galectin-3 and galectin-13 in cases of Intrauterine Growth Restriction (IUGR). Int J Mol Sci. 2016; 17(4): 523, doi: 10.3390/ijms17040523, indexed in Pubmed: 27070577.

30. Boutsikou T, Giotaki M, Boutsikou M, et al. Cord blood galectin-1 and -3 concentrations in term pregnancies with normal restricted and increased fetal growth. J Perinat Med. 2015; 43(3): 305-309, doi: 10.1515/jpm-20130220, indexed in Pubmed: 24717333.

31. Nhan-Chang CL, Romero R, Tarca AL, et al. Characterization of the transcriptome of chorioamniotic membranes at the site of rupture in spontaneous labor at term. Am J Obstet Gynecol. 2010; 202(5): 462.e1462.41, doi: 10.1016/j.ajog.2010.02.045, indexed in Pubmed: 20452490.

32. Hassan SS, Romero R, Tarca AL, et al. The molecular basis for sonographic cervical shortening at term: identification of differentially expressed genes and the epithelial-mesenchymal transition as a function of cervical length. Am J Obstet Gynecol. 2010; 203(5): 472.e1-472.e14, doi: 10.1016/j.ajog.2010.06.076, indexed in Pubmed: 20817141.

33. Than NG, Kim SS, Abbas A, et al. Chorioamnionitis and increased galectin-1 expression in PPROM --an anti-inflammatory response in the fetal membranes? Am J Reprod Immunol. 2008; 60(4): 298-311, doi: 10.1111/j. 1600-0897.2008.00624.x, indexed in Pubmed: 18691335.

34. DiGiulio DB, Romero R, Amogan HP, et al. Microbial prevalence, diversity and abundance in amniotic fluid during preterm labor: a molecular and culture-based investigation. PLoS One. 2008; 3(8): e3056, doi: 10.1371/journal.pone.0003056, indexed in Pubmed: 18725970.

35. Stefanoska I, Tadić J, Vilotić A, et al. Histological chorioamnionitis in preterm prelabor rupture of the membranes is associated with increased expression of galectin-3 by amniotic epithelium. J Matern Fetal Neonatal Med. 2017; 30(18): 2232-2236, doi: 10.1080/14767058.2016.1243100, indexed in Pubmed: 27690725.

36. Ilarregui JM, Bianco GA, Toscano MA, et al. The coming of age of galectins as immunomodulatory agents: impact of these carbohydrate binding proteins in T cell physiology and chronic inflammatory disorders. Ann Rheum Dis. 2005; 64 Suppl 4: iv96-i103, doi: 10.1136/ard.2005.044347, indexed in Pubmed: 16239398

37. Kaya B, Turhan U, Sezer S, et al. Maternal serum galectin-1 and galectin-3 levels in pregnancies complicated with preterm prelabor rupture of membranes. J Matern Fetal Neonatal Med. 2020; 33(5): 861-868, doi: 10.1080/14767058.2019.1637409, indexed in Pubmed: 31242786. 